\title{
Unemployment, SNAP Enrollment, and Food Insecurity Before and After California's COVID-19 Shutdown
}

\author{
Fred Molitor, $\mathrm{PhD}^{1}$; Celeste Doerr, $\mathrm{PhD}^{2}$; Sarah Kehl, $\mathrm{MPH}^{3}$
}

\begin{abstract}
Objectives: To examine whether the decrease in very low food security (VLFS) observed in California shortly after California's coronavirus disease (COVID-19) shutdown remained throughout Federal Fiscal Year (FFY) 2020. To investigate associations among unemployment, Supplemental Nutrition Assistance Program (SNAP) enrollment, and VLFS across FFY 2020.

Methods: Telephone interview responses from mothers from randomly sampled households from lowincome areas throughout California to the 6-item US Department of Agriculture Food Security Survey Module identified VLFS families. Logistic regression examined VLFS rates before vs after California's COVID-19 shutdown, with race/ethnicity, age, and education as covariates. Pearson correlations were calculated for unemployment, SNAP enrollment, and VLFS.

Results: Most (66.4\%) of the 2,682 mothers were Latina. VLFS declined from 19.3\% before to $14.5 \%$ after California's COVID-19 shutdown (adjusted odds ratio, $0.705 ; P=0.002$ ). The correlation for unemployment and SNAP household participation was $0.854(P=0.007)$, and for SNAP participation and VLFS was $-0.869(P=0.005)$.

Conclusions and Implications: Publicly-funded assistance programs may lower food insecurity, even during a time of increased economic hardship. Examining the specific factors responsible for the observed decline in VLFS has merit. Whether VLFS remains below the rate observed before California's COVID-19 shutdown is worthy of ongoing study.
\end{abstract}

Key Words: SNAP, COVID-19, food insecurity, unemployment (J Nutr Educ Behav. 2021;53:1055-1059.)

Accepted September 3, 2021.

\section{INTRODUCTION}

Rising unemployment was one early consequence of the coronavirus disease (COVID-19) pandemic. In California, the seasonally adjusted unemployment rate jumped from $5.3 \%$ in March 2020 to $16.3 \%$ in May $2020^{1}$ after the initiation on March 19, 2020, of California's executive order to stay at home. ${ }^{2}$ From March to May 2020, unemployment across the US climbed from $4.4 \%$ to $13.3 \%{ }^{3}$ By May 2020, unemployment rates were higher for women than men, higher for African American and
Latino individuals than White individuals, and higher for immigrants than nonimmigrants. ${ }^{4,5}$ Early in the pandemic (from March to April 2020), an increase in food insecurity was predicted to follow rising unemployment rates. ${ }^{6-11}$

Subsequent confirmation of the foretold rise in food insecurity was "illustrated by news reports of mileslong lines at food pantries"12 and empirical research. One often-cited study $^{12}(\mathrm{n}=60$ on November 4, 2021; Google Scholar) reported that, during COVID-19, food insecurity across the US had doubled overall and tripled

\footnotetext{
${ }^{1}$ Department of Communication Studies, California State University Sacramento, Sacramento, CA

${ }^{2}$ Public Health Institute, Center for Wellness and Nutrition, Sacramento, CA

${ }^{3}$ CalFresh Healthy Living, California Department of Social Services, Sacramento, CA

Conflict of Interest Disclosure: The authors have not stated any conflicts of interest.

Address for correspondence: Fred Molitor, PhD, Department of Communication Studies, California State University, Sacramento, 1881 Dormity Rd, Rescue, CA 95672; E-mail: fred. molitor@csus.edu

(C) 2021 The Authors. Published by Elsevier Inc. on behalf of Society for Nutrition Education and Behavior. This is an open access article under the CC BY-NC-ND license (http:// creativecommons.org/licenses/by-nc-nd/4.0/)

https://doi.org/10.1016/j.jneb.2021.09.001
}

among households with children. However, the researchers' estimates included adjusting respondent-level survey data to the household level and measures of food sufficiency to food insecurity. The rate of food insecurity before COVID-19 (defined by the researchers as February 2020) was estimated from trends in unemployment from a 2018 survey with items using a past-year recall period. This estimate was used as a comparison to the COVID-19 food insecurity estimates from April 23 to May 19, 2020 , with a recall period of the past month.

More modest estimates in changes in food insecurity following COVID19 are available from studies with more sound methodological approaches. Before vs during COVID-19 comparisons in the short-term found food insecurity to increase by $78.3 \%$ among randomly selected low-income, mostly African American households in Pittsburgh, PA (from March 23 to May 22,2020$)^{13}$; by $32.3 \%$ among a convenience sample of Vermont residents (from March 29 to April 12, 2020) ${ }^{14}$; and by $12.3 \%$ among a 
representative sample of US households (April 23-30, 2020). ${ }^{15}$

However, 2 studies have reported decreases in food insecurity associated with COVID-19-driven, publiclyfunded economic assistance programs. Raifman and colleagues ${ }^{16}$ examined changes in food insecurity among individuals from households earning less than $\$ 75,000$ a year who lost their job during the COVID-19 pandemic (from April 1 to November 11, 2020). Compared with the rate recorded at the initial survey period (April 1-28, 2020), food insecurity declined 4.3 percentage points (PPs) for those receiving unemployment insurance, with or without the $\$ 600 /$ wk Coronavirus Aid, Relief, and Economic Security (CARES) Act supplement. ${ }^{17}$

We found very low food security (VLFS) to decrease by 5.3 PPs shortly after California's COVID-19 shutdown and subsequent economic downturn (from April 27 to July 21, 2020) among households from lowincome areas with children across California. ${ }^{18}$ The decline in VLFS coincided with California using Families First Coronavirus Response Act $^{19}$ funds to raise the Supplemental Nutrition Assistance Program (SNAP; CalFresh in California) benefit to the maximum allowable on the basis of household size and using CARES Act funds to support the distribution of Pandemic EBT (P-EBT) cards, reaching 93\% of children from CalFresh households and redeemed for $\$ 986$ million in food purchases. These benefits were provided when 463,725 families were enrolled in CalFresh, a 21\% increase from February to June 2020. Data from our now available Federal Fiscal Year (FFY) 2020 survey of mothers from low-income California households with children can be used to investigate the potential of economic assistance programs to address food insecurity in the longer term.

The purpose of the current study was to examine changes in VLFS following California's COVID-19 shutdown in light of the rise in unemployment coupled with existing and COVID-19-specific economic assistance programs available to lowincome families in California. Our first study objective was to examine whether the previously-reported ${ }^{18}$ initial decrease in VLFS observed following California's COVID-19 shutdown remained throughout FFY 2020. The second objective was to investigate the associations of monthly changes in unemployment, CalFresh enrollment, and VLFS rates across FFY 2020.

\section{METHODS}

Data for the current study came from the California Family Health Study (CFHS), an annual telephone survey of mothers or female caregivers with child(ren) 5-17 years from households eligible for the Supplemental Nutrition Assistance Program-Education (SNAP-Ed; CalFresh Healthy Living in California). Survey responses are used to track population-based US Department of Agriculture (USDA) SNAP-Ed evaluation framework indicators. $^{20}$ The youngest female caregivers who self-identify as mothers (subsequently referred to as "mothers") are recruited to participate in 24-hour dietary recall interviews; supplemental survey items assess demographics (race/ethnicity, age, and education), physical activity, and food security. Interviews are conducted throughout each FFY (October through September). However, in FFY 2020, survey operations were suspended twice: From March 15 to April 26, 2020, in response to the governor's executive order requiring all nonessential business to close $^{2}$ (California's COVID-19 shutdown), and then from July 22 to August 29, 2020, because of an interviewer testing positive for COVID-19. The current study was approved by the California Health and Human Services Agency, Committee for the Protection of Human Subjects. Consent was documented for all participants.

The sampling frame was the MediCal Eligibility Data System (MEDS). Individuals are entered into the MEDS when $\geq 1$ household residents apply for benefits administered by the State of California, including Medi-Cal and CalFresh. The MEDS is maintained by the California Department of Health Care Services, which sends records to the research team only for individuals eligible for CalFresh Healthy Living from households $\leq 185 \%$ of the federal poverty level. Records are removed from the MEDS when an individual's household has not been eligible for CalFresh for $\geq 1$ month out of the previous 12 months.

In FFY 2020, sampling of households with $\geq 1$ adult female and child aged 5-17 years was conducted quarterly. Households selected at random were sent a letter of introduction to the study in English or Spanish. Bilingual staff verified by phone household eligibility and the youngest mother. The youngest mother was selected in households with multiple mothers (eg, multigenerational families, sisters with children cohabitating) because she was most likely to have a child aged 5 -17 years. Mothers were offered a \$15 gift card to participate in a telephone interview scheduled at the end of the screening and recruitment calls.

In subsequent interviews $(\mathrm{n}=$ 2,814), VLFS households were identified when mothers provided affirmative responses to $\geq 5$ items of the USDA 6-item Food Security Survey Module. $^{21}$ Mothers were asked their age and highest level of education and the following questions: "Are you Hispanic, Latina, or of Spanish origin?"; "What is your race? You may answer more than 1"; "Are you American Indian or Alaska Native, Asian, Black or African American, Native Hawaiian or other Pacific Islander, White, or other?"

We examined VLFS before (from November 21, 2019 to March 14, 2020) vs after (from April 27 to September 29, 2020) California's COVID-19 shutdown using logistic regression. Covariates were race/ethnicity (African American and White individuals each coded as 1 with Latina, other, and mothers with missing data, who all reported similar levels of VLFS, as the reference group), age centered on the mean, and education $(<$ high school the reference to high school graduate $=1$ and $\geq$ some college $=1$ ). We used publicly available data from the State of California Employment Development Department ${ }^{1}$ and the California Department of Social Services (CDSS), ${ }^{22}$ with interview responses from the CFHS, to examine monthly trends in the seasonally adjusted unemployment rate, household participation in CalFresh, and VLFS across FFY 2020. For these trends, each variable was standardized to 0 for its value on November 2019: unemployment $=3.9 \%$; CalFresh 
households $=2,162,412$; and VLFS $=$ $19.1 \%$. Relatively few interviews occurred in April $(\mathrm{n}=32)$ and August $(n=28)$ because of the suspension of survey operations. Accordingly, rates for VLFS were calculated from and reported as the same for interviews occurring during April and May and August and September.

Pearson correlation coefficients were calculated among unemployment, CalFresh participation, and VLFS from February to September 2020, a timeframe selected to represent the month before California's COVID-19 shutdown through FFY 2020. Data cleaning, coding, and analyses were conducted with SPSS (version 27.0, IBM Corp, Armonk and NY, 2020).

\section{RESULTS}

Valid data were available from 2,682 mothers. Excluded from the analyses were records missing all Food Security Survey Module ${ }^{21}$ items $(n=123)$ or the interview date $(n=9)$. A total of 1,780 mothers $(66.4 \%)$ were Latina, 412 (15.4\%) were White, and 357 (13.3\%) were African American. A total of $124(4.6 \%)$ mothers were coded as other and $9(0.3 \%)$ as missing for race/ethnicity.

Very low food security dropped 4.8 PPs (adjusted odds ratio, 0.705; $P=$ 0.002), following California's COVID19 shutdown through September 2020 (Table). As seen in the Figure, both the unemployment rate and the number of CalFresh households remained stable before California's COVID-19 shutdown. During March 2020, these indicators increased by 1.4 and 1.3 PPs. One month following California's COVID-19 shutdown, unemployment increased by 11.6 PPs. Accordingly, the PP increase for CalFresh households followed the same trajectory. The

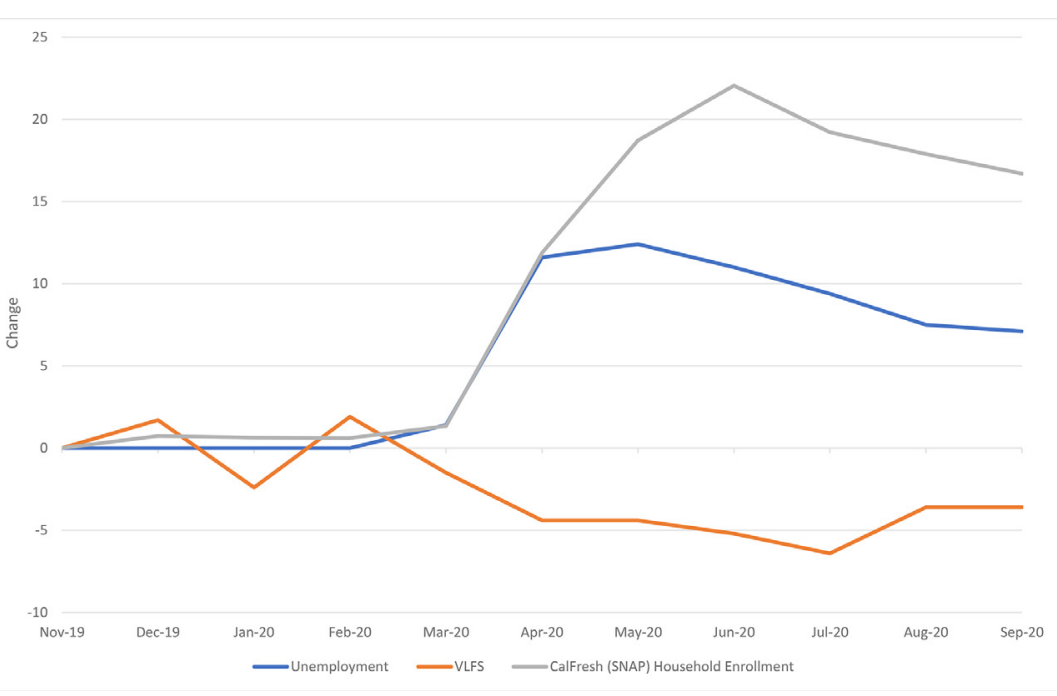

Figure. The percentage point change in the seasonally adjusted unemployment rate, CalFresh (Supplemental Nutrition Assistance Program [SNAP]) household participation, and very low food security (VLFS) among 2,682 California households with children, Federal Fiscal Year 2020. Correlations for unemployment and CalFresh $=0.854 \quad(P=0.007)$; Unemployment and VLFS $=-0.869(P=0.005) ;$ and CalFresh and VLFS $=-0.869(P=0.005)$.

unemployment rate topped out at 16.3\% (12.4 PPs from November 2019) in May 2020, then declined each month to $7.1 \%$ by September 2020 . CalFresh household participation continued to increase from February 2020 to June 2020 (22.1 PPs from November 2019), then began a similar monthly descent as the unemployment rate. The rate for VLFS fluctuated from November 2019 through February 2020 by $1.7 \pm 2.4$ PPs. From March to July 2020, VLFS descended 6.4 PPs. In August 2020, the rate of VLFS increased from the low of $12.7 \%$ in July 2020 to $15.5 \%$ in August and September 2020, corresponding with the decline in CalFresh participation.

A correlation of $0.854\left(r^{2}=0.729\right.$; $P=0.007)$ was observed between unemployment and CalFresh participation. The relationships between unemployment and CalFresh participation and VLFS were both -0.869 $\left(R^{2}=0.755 ; P=0.005\right)$.

\section{DISCUSSION}

We found a 4.8 PP decline for VLFS following California's COVID-19 shutdown among a representative sample of households with children. Similarly, Raifman et $\mathrm{al}^{16}$ reported a $4.3 \mathrm{PP}$ decrease in food insecurity among a nationally representative sample of individuals who became unemployed during COVID-19. Both study findings came from lowerincome population-based samples during times of elevated unemployment; both studies also linked reductions in food insecurity to economic assistance programs. The assessment by Raifman et $\mathrm{al}^{16}$ of such programs

Table. Prevalence and Adjusted Odds of VLFS, Before vs After California's COVID-19 Shutdown, Among 2,682 California Households With Children, Federal Fiscal Year 2020

\section{Period}

Before COVID-19 shutdown (from November 21, 2019 to March 14, 2020)

After COVID-19 shutdown (from April 27 to July 21, 2020)

After COVID-19 shutdown (from August 30 to September 29, 2020)

\begin{tabular}{lllc} 
& \multicolumn{3}{c}{ VLFS } \\
\cline { 2 - 4 } $\mathbf{n}$ & \multicolumn{2}{c}{ Prevalence, \% } & AOR $(\mathbf{9 5 \%} \mathbf{~ C l})^{\mathrm{a}}$ \\
1,773 & 19.3 & 19.3 & 1.0 \\
581 & 14.0 & 14.5 & $0.705(0.566-0.878)^{\mathrm{C}}$ \\
328 & 15.3 & &
\end{tabular}


was more direct; they asked survey participants whether they had received unemployment insurance in the past 2 weeks. We interpret the decline in VLFS under the assumption that mothers participating in the FFY 2020 CFHS, who were sampled from a frame in which household members had applied for CalFresh during the previous year, were receiving CalFresh when they were interviewed. Accordingly, the increase in CalFresh benefits from Families First Coronavirus Response Act funds and the receipt of P-EBT cards may have provided families with the resources to purchase additional quantities of foods sufficient to move beyond the VLFS threshold, as assessed by the Food Security Survey Module. ${ }^{21}$ In fact, from May through September 2020, 2 rounds of P-EBT cards were distributed to CalFresh families with children with 5.3 million cards redeemed for $\$ 1.73$ billion in food purchases (May 5, 2021, email from Hares Rahimzei, PEBT Project Lead, CDSS). Additional resources to purchase food after California's COVID-19 shutdown could have come from CARES \$600/wk supplement funds for those CalFresh households experiencing unemployment. To the degree that these assumptions are accurate, the findings from these 2 studies suggest that publicly-funded economic assistance programs may play a role in lowering food insecurity, even during a time of increased economic hardship. Finally, the focus on low-income populations that did or likely received economic assistance might explain why the findings from Raifman et $\mathrm{al}^{16}$ and our study contradict the results from other investigations of COVID-19 and food insecurity. $^{13-15}$

Examining the monthly trends and nature of the relationships among unemployment, CalFresh household participation, and VLFS observed in the current study, the following sequence of events may have unfolded in California in FFY 2020: rising CalFresh participation was driven by increasing unemployment following the state's COVID-19 shutdown. Enhanced CalFresh benefits, P-EBT cards, and/or CARES unemployment benefits provided the means to families from low-income areas to have more resources than before COVID-19 to purchase food. By August 2020, with CARES unemployment benefits ending in July, and the decline in CalFresh participation, presumably as household members returned to work, families may have had more limited resources to purchase food, and VLFS rates began to increase.

Our trend data also revealed that the PP increase in CalFresh participation exceeded that for unemployment from April to May 2020 and took a month longer to begin a decline. Historically, nutrition assistance program participation has correlated with but lagged behind changes in economic conditions. $^{23}$ As the California economy improved, mothers recruited for the current study or family members who contributed to the household income may have had to rely on CalFresh longer before returning to work than workers in higher-paid, more skilled fields of employment.

Limitations of our study include the potential for self-report biases. The CFHS recruits only families with mothers, and P-EBT cards were distributed only to families with children. Thus, the observed declines in VLFS may not have occurred to the same extent among CalFresh households without mothers or children. The CFHS is designed to track USDA SNAP-Ed evaluation framework indicators ${ }^{20}$ among a population eligible for CalFresh Healthy Living, with a survey instrument including limited demographic items and purposely excluding questions related to CalFresh enrollment, employment status, or the receipt of unemployment or other benefits. These measures would have provided greater support for the assumption that economic assistance reduced VLFS among our study population.

The question remains whether VLFS rates will trend back to preshutdown levels as COVID-19 unemployment and CalFresh benefits are phased out. Current federal \$300/ wk supplemental unemployment benefits end September 4, 2021. ${ }^{24}$ Since March 2020, CalFresh recipients have been receiving the maximum benefits on the basis of household size. ${ }^{25}$ On April 1, 2021, the USDA approved all CalFresh households to receive $\$ 95 /$ month. $^{26}$ This emergency allotment has been approved monthly and will end once a state or national emergency declaration is no longer in place. ${ }^{26}$ CalFresh benefits also increased by $15 \%$ on January 1 , 2021, and the American Rescue Plan Act of 2021 extended this increase through September 30, 2021 (July 21, 2021, email from Kathy Yang, Chief of the CalFresh Policy \& Employment Bureau, CDSS). Finally, California is sending a third (and final) round of P-EBT cards to CalFresh families (July 20, 2021, email from Hares Rahimzei, P-EBT Project Lead, CDSS). Notwithstanding, in August 2021, the USDA released the reevaluated Thrifty Food Plan, ${ }^{27}$ increasing the monthly SNAP benefits to $\$ 36$ per person, on average, effective October $1,2021 .^{28}$

\section{IMPLICATIONS FOR RESEARCH AND PRACTICE}

Our findings suggest that responsive state economic assistance programs with adequate federal funds may play a role in reducing food insecurity. The specific factors responsible for the apparent decline in VLFS among households from low-income areas should be investigated. These might include having greater income overall and specifically for food purchases from enhanced CalFresh and/or unemployment benefits than before the COVID-19 shutdown, the restrictions to purchase only food and beverage items using the CalFresh benefits, or factors such as families using food dollars for more economical home-prepared rather than restaurant meals during times of unemployment and shelter-in-place restrictions. The study of increased SNAP benefits beginning FFY 2022 on food security is also of value. Finally, cost-benefit studies could investigate the initial or potential longer-term decline in VLFS in relation to the prevention of the negative health outcomes that have been associated with food insecurity. ${ }^{29,30}$

\section{REFERENCES}

1. State of California, Employment Development Department. Civilian unemployment rate for US and California. 2020. https://data.edd.ca.gov/ Labor-Force-and-UnemploymentRates/Civilian-Unemployment-Rate- 
for-US-and-California/x7g9-zu4h. Accessed August 27, 2021.

2. State of California, Executive Department. Executive Order N-33-20. https://covid19.ca.gov/img/N-33-20. pdf. Accessed August 27, 2021.

3. U.S. Bureau of Labor Statistics. Civilian unemployment rate. https://www.bls. gov/charts/employment-situation/ civilian-unemployment-rate.htm. Accessed August 27, 2021.

4. California Budget \& Policy Center. Women and people of color take biggest hits in California job losses. https://calbudgetcenter.org/resources/ women-poc-take-hits-in-californiasjob-loss/. Accessed August 27, 2021.

5. Kochhar R. Unemployment rose higher in three months of COVID-19 than it did in two years of the Great Recession. Pew Research Center; 2020. https://www.pewresearch.org/ fact-tank/2020/06/11/unemployment-rose-higher-in-three-months-ofcovid-19-than-it-did-in-two-years-ofthe-great-recession/. Accessed August 27, 2021.

6. Feeding America. The Impact of the Coronavirus on Food Insecurity in 2020 \& 2021. Feeding America; 2021. https:// www.feedingamerica.org/sites/default/ files/2021-03/National\%20Projections \%20Brief_3.9.2021_0.pdf. Accessed August 27, 2021.

7. Feeding America. The Impact of the Coronavirus on Child Food Insecurity. Feeding America; 2020. https://www. feedingamerica.org/sites/default/files/ 2020-04/Brief_Impact $\% 20$ of $\% 20 \mathrm{Co}$ vid $\% 20$ on $\% 20$ Child $\% 20$ Food\%20Insecurity\%204.22.20.pdf. Accessed August 27, 2021.

8. Kinsey EW, Kinsey D, Rundle AG. COVID-19 and food insecurity: an uneven patchwork of responses. J Urban Health. 2020;97:332-335.

9. Van Lancker W, Parolin Z. COVID-19, school closures, and child poverty: a social crisis in the making. Lancet Public Health. 2020;5:E243-E244.

10. Wolfson JA, Leung CW. Food insecurity and COVID-19: disparities in early effects for US adults. Nutrients. 2020;12:1648.

11. Lauren BN, Silver ER, Faye AS, et al. Predictors of households at risk for food insecurity in the United States during the COVID-19 pandemic. Public Health Nutr. 2021;24:3929-3936.

12. Schanzenbach DW, Pitts A. How Much has Food Insecurity Risen? Evidence From the Census Household Pulse Survey. Northwestern Institute for Policy Research;
2020. https://www.ipr.northwestern. edu/documents/reports/ipr-rapidresearch-reports-pulse-hh-data-10-june2020.pdf. Accessed August 27, 2021.

13. Dubowitz T, Dastidar MG, Troxel WM, et al. Food insecurity in a lowincome, predominantly African American cohort following the COVID-19 pandemic. Am J Public Health. 2021; 111:494-497.

14. Niles MT, Bertmann F, Belarmino EH, Wentworth T, Biehl E, Neff R. The early food insecurity impacts of COVID-19. Nutrients. 2020;12:2096.

15. Morales DX, Morales SA, Beltran TF. Racial/ethnic disparities in household food insecurity during the COVID-19 pandemic: a nationally representative study. J Racial Ethn Health Disparities. 2021;8:1300-1314.

16. Raifman J, Bor J, Venkataramani A. Association between receipt of unemployment insurance and food insecurity among people who lost employment during the COVID-19 pandemic in the United States. JAMA Netw Open. 2021;4:e2035884

17. H.R.748 - CARES Act. Public Law No. 116-136. (2020). https://www. dol.gov/agencies/whd/pandemic/ffcraemployee-paid-leave. Accessed August 27, 2021.

18. Molitor F, Doerr C. Very low food security among low-income households with children in California before and shortly after the economic downturn from COVID-19. Prev Chronic Dis. 2021;18:e01.

19. U.S. Department of Labor. Families First Coronavirus Response Act: employee paid leave rights. https://www.congress. gov/bill/116th-congress/house-bill/748/ text?q $=\% 7 \mathrm{~B} \% 22$ search $\% 22 \% 3 \mathrm{~A} \% 5 \mathrm{~B} \%$ $22 \mathrm{hr}+748 \% 22 \% 5 \mathrm{D} \% 7 \mathrm{D} \& \mathrm{r}=1 \& \mathrm{~s}=1$. Accessed November 4, 2021.

20. United States Department of Agriculture. SNAP-Ed Evaluation Framework. https://snapedtoolkit.org/framework/ index/. Accessed August 27, 2021.

21. United States Department of Agriculture. U.S. Household Food Security Survey Module: Six-Item Short Form. Economic Research Service, USDA; 2012. https://www.ers.usda.gov/media/ 8282/short2012.pdf. Accessed August 27, 2021.

22. State of California, California Department of Social Services. CalFresh data dashboard: monthly participation for CalFresh households; 2020. https:// public.tableau.com/profile/california. department.of.social.services\#!/
vizhome/CFdashboard-PUBLIC/ Home?publish=yes. Accessed August 27, 2021

23. Hanson K, Oliveira V, United States Department of Agriculture. How Economic Conditions Affect Participation in USDA Nutrition Assistance Programs. US Department of Agriculture; 2012. https://www.ers.usda.gov/webdocs/ publications/43667/32191_eib100.pdf? $\mathrm{v}=8079.2$. Accessed August 27, 2021.

24. State of California, Employment Development Department. Coronavirus 2019 (COVID-19). https://edd.ca. gov/about_edd/coronavirus-2019.htm. Accessed August 27, 2021.

25. California Department of Social Services. All county welfare Directors Letter (CalFresh Implementation of the Families First Coronavirus Response Act: CalFresh Emergency Allotments). https://www.cdss.ca.gov/Portals/9/ Additional-Resources/Letters-and-Notices/ACWDL/2020/ACWDL_04-0220(2).pdf. Accessed August 27, 2021.

26. California Department of Social Services. All county welfare Directors Letter (CalFresh Emergency Allotments for July 2021). https://cdss.ca.gov/Portals/ 9/Additional-Resources/Letters-andNotices/ACWDL/2021/ACWDL_CalFreshEmerAllotments_6-24-21.pdf? ver $=2021-06-25-075747-090$. Accessed August 27, 2021.

27. United States Department of Agriculture. Thrifty Food Plan, 2021. US Department of Agriculture; 2021. https://fns-prod.azureedge.net/sites/ default/files/resource-files/TFP2021. pdf. Accessed August 27, 2021.

28. United States Department of Agriculture. Estimates increase in SNAP benefits, FY 2022 by state, from reevaluated Thrifty Food Plan. https:// www.fns.usda.gov/TFP/state_table. Accessed August 27, 2021.

29. Gundersen C, Ziliak JP. Food insecurity and health outcomes. Health Aff. 2015;34:1830-1839.

30. Banerjee S, Radak T, Khubchandani J, Dunn P. Food insecurity and mortality in American adults: results from the NHANES-Linked Mortality Study. Health Promot Pract. 2021;22:204-214.

\section{ORCIDs}

Fred Molitor: http://orcid.org/00000001-7871-9064

Sarah Kehl: http://orcid.org/00000002-3249-8443 